Data \& Analytics For Good •

\title{
Food Recovery Efforts for Upstream and Downstream Benefits (I1.A2)
}

Benjamin Farzley, Amelia Holcomb, William Hadley, Ronald Freeze

Published on: Aug 05, 2021

License: Creative Commons Attribution 4.0 International License (CC-BY 4.0). 


\begin{abstract}
Hogs don't waste food!!! Razorback Food Recovery (RFR), a student led campus food rescue program, works to reduce food waste at the University of Arkansas. RFR's mission addresses three of the United Nations Sustainable Development Goals:
\end{abstract}

- Goal \#2 Zero Hunger

- Goal \#12 Responsible Consumption and Production

- Goal \#13 Climate Action

The program achieves these goals by donating food to people who are food insecure, sharing data with dining services to better guide their purchasing and decision-making process, and reducing emissions by diverting food waste from the landfill. The progress toward these goals is guided by the EPA Food Recovery Hierarchy, a model to show the best options for addressing excess food. This paper will show the program's impact and how it has successfully operated. The program has recovered a smaller amount of food in the past few years, achieving its goal of helping the dining services work toward source reduction and working toward a system where a minimal amount of food is left over from each dining location.

RFR tracks data through food recovery processes across the University of Arkansas. The data features the variables: weight (pounds), date of recovery, timestamp, food group, food more specific, food storage, quantity of pans used, day of the week, day of the month, month of the year, year, hour, and location of food. The recovered food is measured in physical weight to identify how much physical weight is being diverted from landfills. There are 6,998 entries with 11 different food recovery locations associated with this data analysis from 2018 and 2019. A performance example is Fulbright Dining Hall, which had a 65.29\% decrease in amount of grains recovered from 2,368 lbs in 2018 to 822 lbs in 2019. The data can be used in the following ways:

- Identify trends to help completely minimize food waste throughout the academic school year;

- Identify key methods for waste reduction for both seasonal and stagnant attributes; and

- Forecast future food production in the dining halls.

\title{
Razorback Food Recovery Overview
}

\section{Brief History}


RFR at the University of Arkansas was first introduced in 2014. A curious student noticed the dining halls on campus were throwing away a copious amount of untouched food. The university's Center for Community Engagement worked with the student activists and the dining hall staff to work out the logistics and standards needed to start a program. They developed a solution for a team of volunteers to repackage the dining hall's leftover food and transport it to community agencies serving people who are food insecure. The volunteers started the program by recovering unused food from the Arkansas Union retail stores, which is collected in the Union "dungeon" once a week and then gradually expanded into five dining halls on campus. The mission statement of RFR reads: "Razorback Food Recovery enacts change by helping campus dining outlets prevent food overproduction, distributing excess food to people who are food insecure, and educating Northwest Arkansas stakeholders in sustainable food consumption."

The University of Arkansas School of Law Food Recovery Project, a leading national resource on legal issues surrounding the donation of excess food, and the University of Arkansas Office for Sustainability helped implement the program and facilitated relationships with Chartwells, the managing organization for all campus dining halls. Campus efforts to start food recovery led the United States Environmental Protection Agency (EPA) to present the Office for Sustainability with an Achievement Award in 2013 for campus work on the EPA's food recovery challenge. RFR also received a grant from Tyson Foods early in its inception, and part of the funding was used to share the successful recovery model. In 2015, RFR hosted a summit for Arkansas food programs and in 2016 RFR hosted the conference for The Campus Kitchen Project, a national organization that advocates to reduce or eliminate hunger on college campuses. RFR has also worked with the Food Recovery Network, an organization that helps students start their own food recovery operations.

Being a part of the Volunteer Action Center on the University of Arkansas campus helps the program reach students for volunteer recruitment and general awareness. This structure maintains the continuity of the program by securing both volunteers and students to join the leadership board. Advisors have institutional knowledge about the program's history and long-standing relationships with the dining hall staff to guide students and the program. The resulting organization, Razorback Food Recovery, oversees the processes set up to reduce food waste and to serve the NorthWest Arkansas's (NWA) food security needs. The initial goals of RFR were to assist in reducing NWA's food insecurity which benefits UN Goal \#2 Zero Hunger. However, the 
sharing of this data with Chartwells has also helped them achieve a more Responsible Production Consumption (UN Goal \#12) of their services. Chartwells utilizes the given data and analyzes the key variables of weight and dining hall (․ppendix A: Data Dictionary). With these variables, Chartwells is able to understand where areas of improvement need to be made to more responsibly produce. Finally, the reduced generation of food waste allows RFR to provide measures to identify the quantity of food diverted from landfills and the subsequent creation of methane in order to fulfill UN Goal \#13 Climate Action.

\section{Recovery and the EPA Hierarchy}

The Razorback Food Recovery program has set in place efficient ways to obtain unused and unwanted food from catering events and every dining hall on campus. Once volunteers are selected for each of the dining halls, the board for RFR initiates indepth training for them on the program, the recovery process, the distribution process, data collecting, and outcome of recovering food. Once recovery starts, each volunteer goes to one of five dining halls/catering venues. There are five dining halls that students volunteer to recover food: 1) Fulbright Dining Hall, 2) Brough Dining Hall, 3) Pomfret Dining Hall 4) Arkansas Union and the 5) Jones Center. Within the dining halls, the cooks and workers provide food that is unused that meets the basic food safety requirements. Razorback Food Recovery provides gloves, hairnets, shoe covers, pans, and lids in order to package the food safely. Once the food is panned, the volunteers fill out a response form that has eleven trackable variables such as weight, food group, food description, number of pans used, dining hall location, and storage method. After data entry, a distribution driver visits each dining hall that is recovering food on that day and takes the food to one of five community partners. RFR's community partners are Salvation Army of NWA, Yvonne Richardson Community Center, Lifesource International, 7 Hills Homeless Shelter, and University of Arkansas's Full Circle Food Pantry. Once the food is delivered, the agency utilizes the recovered food in whatever way best suits their clients and operations. The process developed by RFR follows the general guidance of the EPA Food Recovery Hierarchy (EPA, 2020) (Figure 1).

The EPA Food Recovery Hierarchy (EPA FRH) guides decision-making and models priorities for RFR. RFR impacts three of the EPA Food Recovery Hierarchy guidelines: 1) Source Reduction (UN Goal 12; UN Goal 2) Feed Hungry People (UN Goal 2) and 3) Landfill avoidance (UN Goal 13). The best way to conserve resources and allocate them well is to first focus on the Source Reduction of waste 


\section{Figure 1:}

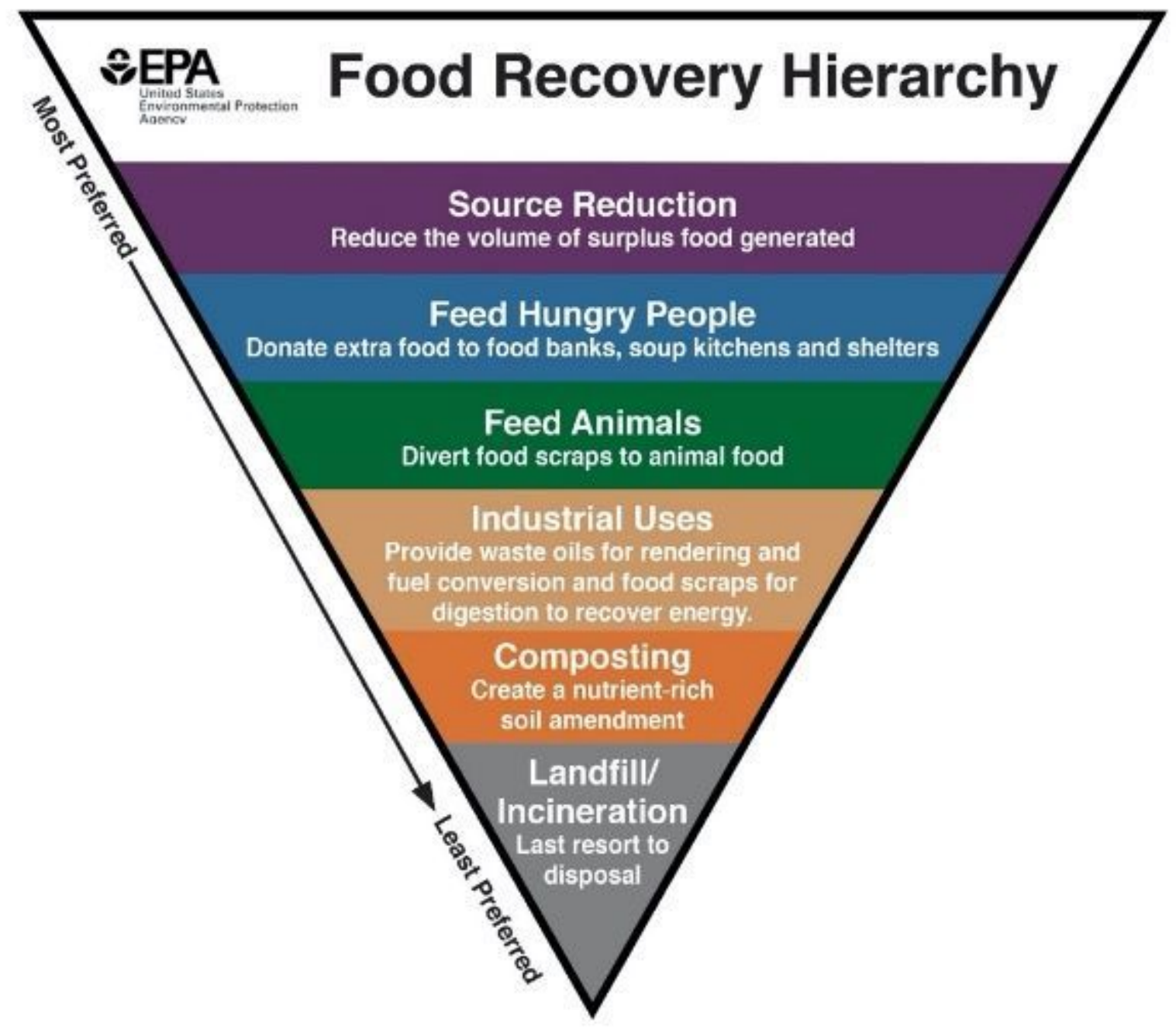

by only producing the amount of food needed (EPA FRH, UN Goal 12) (Figure 1). RFR tracks the data associated with its donations to identify the types of food that is being produced in excess and provides this information back to Chartwells. Second, extra food should be used to feed hungry people (UN Goal 2). RFR works toward this goal by donating collected food.

These two goals identify RFR's competing interests: by reducing excess food production, less donated food is available for feeding the community needs. Because there is still extra food being produced by the campus dining providers, RFR is able to step in and feed people while avoiding sending the food to the compost pile or landfill (UN Goal 13). 


\section{UN Goal 12 - Responsible Consumption and Production}

UN Sustainable Development Goal 12 is focused on efficiently using resources to sustainably support populations. UN Goal 12 also aligns with the most preferred guidance method, Source Reduction, of the EPA FRH (Figure 1). Some of the targets to achieve UN Goal 12 by 2030 include halving per capita global food waste at the retail and consumer levels, substantially reducing "waste generation through prevention, reduction, recycling and reusing, and achieving the sustainable management and efficient use of natural resources" (United Nations, 2020). RFR and the sharing of the data collected with Chartwells supports both the aspects of responsible production and responsible consumption.

On the production side, RFR tracks the excess food dining halls produce and shares it with Chartwells. This sharing of data is designed to give the dining hall directors and chefs specific data about the conditions that lead to extra food being produced. Chartwells can then use this information to better predict the amount of food they need to prepare for meals. The result for Chartwells is a monetary savings by preventing the ordering of too much food and contributing to less excess food in general.

\section{UN Goal 2 - Zero Hunger}

UN Sustainable Development Goal 2 seeks to end hunger, eliminate food insecurity, improve nutrition, and promote sustainable agriculture (United Nations, 2020). UN Goal 2 also aligns with the $2^{\text {nd }}$ most preferred guidance method, Feed Hungry People, of the EPA FRH (Figure 1). As with many campus communities, the University of Arkansas and the larger Northwest Arkansas area contain a diversity of income levels, socioeconomic backgrounds, and accessibility levels. This leads to an equally diverse, and often counter-intuitive, set of societal challenges. Razorback Food Recovery was founded to address the large level of food insecurity present in the community.

Food insecurity is a significant problem both on and off campus. According to research from the University of Arkansas's Center for Community Engagement, only 39\% of students in 2016 were highly food secure (Lisnic, 2016), while $22 \%$ were marginally food secure, $20 \%$ experienced low food security, and 18\% experienced very low food security. Arkansas also has the country's second highest rate of child food insecurity at 23.2 percent. These numbers have likely increased as a result of the COVID-19 pandemic, furthering the importance of food recovery to solve this problem (Lisnic, 2016) (Kellams, 2020). 


\section{UN Goal 13 - Climate Action}

UN Sustainable Development Goal 13's purpose is to address climate change. UN Goal 13 also aligns with the last guidance method, Landfill, of the EPA FRH (Figure 1). The Landfill goal for food waste disposal is actually an avoidance method in alignment with UN Goal 13. RFR, by tracking the food waste from the dining halls, can identify the level of food waste avoidance from being placed in a landfill. The steps to reach UN Goal 13 include a green transition that accelerates the "decarbonization of all aspects of the economy" in order to slow greenhouse gas emissions and limit global warming (United Nations, 2020).

RFR's focus on source reduction and diversion of food waste leads to fewer emissions from the production, transportation, and packaging of the ingredients dining halls would use. Additionally, RFR diverts good, uneaten food from the landfill and city compost facility. In a landfill, the food waste would generate methane, a greenhouse gas about 30 times as potent as carbon dioxide (EPA, 2020). As of December 2020, RFR has successfully diverted $222,107 \mathrm{lbs}$ of food, since inception, from the landfill and industrial compost sites. This diversion reduced the methane that would have been released from a landfill.

\section{Data Summary}

\section{Overview}

RFR has been collecting data since its inception in 2014. Improvements in the collection of data continued to occur as dining halls were added to the food recovery. The data and data analysis were shared with Chartwells to assist them in achieving UN Goal 12 (Responsible Production). Due to the data collection improvements achieved during the program's growth, this analysis makes use of two years of RFR data collection (January $1^{\text {st }}, 2018$ and December 16 $\left.{ }^{\text {th }}, 2019\right)$. This timeframe was selected to compare year-to-year monthly data and to show: 1) Chartwells' progress on food production in order to eliminate waste; 2) food delivered to community partners; and therefore 3) food diverted from landfills.

The data was collected by student volunteers. Each data form submission records the date timestamp of recovery, dining hall, weight of food, food group, food more specific (actual title of dish served), food storage method, quantity of pans used, and size of pans. The student volunteer(s) weigh the food. Data is input by volunteers through a Google form and once submitted, the information goes directly into a Google Sheets 
document. Weight of the food is our most valuable variable when seeking solutions to reduce that weight semester to semester.

\section{Data Tracking Improvements}

RFR has experience continuous improvement in its way of tracking data through a focus of reducing input error and adding internal controls. The first steps for quality control of our data collection and input include putting volunteers through training in order to learn both proper food safety measures and the correct way to weigh/track the food. They are taught to separate food by each item and food group so that the program can get the tracking data desired. When the program started in 2014, RFR tracked the recovery data through the Google software, AppSheets. AppSheets allowed RFR to create a data tracking app for the student volunteers to log the data in and transfer them into a Google Sheets spreadsheet. Each dining hall had its own Google Sheet for each semester.

This method was used up until 2017 when Google Forms became a more viable way to track the data. Google Forms allowed for all recovery data to be input into a single sheet. Volunteers would access the Google Form through their phones and select items from a dropdown box for each variable other than weight and "food more specific". Google Forms have been a more streamlined way to input the data as RFR tries to make it as easy as possible for the volunteers, while also getting the most accurate input. These process improvements have allowed RFR to obtain cleaner data by adding every input in a single sheet. This in turn increased the reliability of the data since all the users were using the same interface on an individual response form. Data outliers were minimized through this process. Beginning in 2019, a control was set in place to have an RFR board member at each individual shift so that food safety measures and proper data tracking is imposed. There will be a never-ending trend of improvements in tracking recovery data in order to eliminate food waste at the University of Arkansas.

\section{Class Partnership}

Part of the RFR Program success is due to its partnership with the upper-level Information Systems course at the University of Arkansas known as ISYS 4393: Applied Business Analytics. RFR has tracked data since its inception in 2014 but lacked the appropriate analytical collections methods to interpret the data. Beginning in 2018, the program began to utilize this class. This partnership aided the RFR program by running analytics on data in order to help Chartwells minimize food waste 
within each dining hall, throughout campus, and teach others on how the data can show trends and areas of improvement.

At the beginning of every semester, the Data Intern creates a presentation, showcasing what the program is, how data is obtained, variables used, and questions that the program wants answered through the data. Typical questions that have been asked in the past include:

- What trends are there in each specific dining hall with regard to food waste?

- What is the monthly analysis of food waste from each dining hall? What is the weekly analysis of food waste from each dining hall?

- Are there seasonal trends within the dining halls?

At the end of the semester, the group presents a report to members of the RFR program, Chartwells Dining Services, and the class instructor. The analysis each semester provides vital information to Chartwells to see trends with food waste in dining halls and see areas in which each dining hall is creating food waste. Chartwells then uses this given information to make decisions about how much of each food group to purchase and make more responsible decisions in the production and distribution of food to help eliminate the food waste within the dining halls.

\section{Results}

The primary goal of the RFR program is to eliminate food waste at the University of Arkansas. This can be achieved through the elimination of "food waste" by delivering the unused food to local food pantries or by using the data associated with the collection to learn how to better anticipate the level of food preparation to reduce the unused food. The partnership between the RFR program and Chartwells Dining Services at the University of Arkansas has resulted in substantial success in eliminating food waste. The campus staff, chefs, and nutritionists have used the data provided by RFR to aid them in the daily production of food in the dining halls. Chartwells uses the data from RFR on campus to assess items that are typically being sent to recover more often than others, which in turn helps them tighten production on leftover items. In particular, removing all menus from catering operations has led to a significant decline in waste since food that is ordered is food that is produced. The improvements are most visible in three of the dining halls: Fulbright, Pomfret, and Brough. These are also the largest dining halls on campus.

\section{Figure 2:}




\section{UN Goal Contributions - Three Dining Halls}

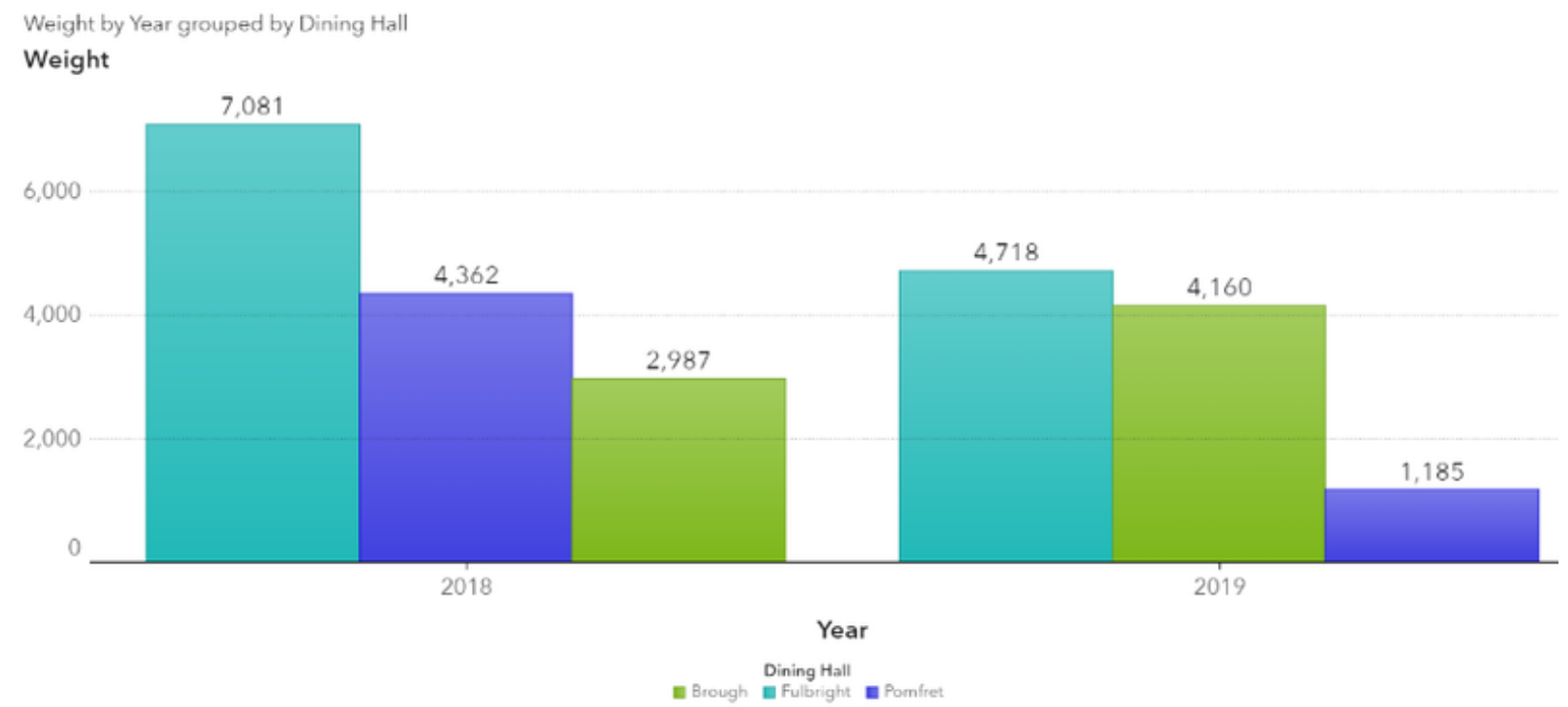

When evaluating the progress toward achieving the UN Goals, we started with the dining halls that produced the most "food waste." It was important that the selected dining halls had a relatively mature pickup schedule from year-to-year in order to not miss catching food that could go to the local food pantries and thereby help with the reduction of hunger and food insecurity. Since we are looking at the comparison of 2018 and 2019 (thereby avoiding the COVID-19 impact), the dining halls with the largest total recovered food (by weight) in 2018 were used to assess progress toward UN Goal 12 (Responsible Production). The three dining halls selected, in order of most food collected in 2018 were Fulbright (7,081 lbs), Pomfret (4,362 lbs) and Brough $(2,987)$ (Figure 2). These three dining halls are where students generally eat on campus as they are strategically placed around dorms and classrooms. Achievements for each of the three dining halls are provided below.

\section{Figure 3:}

\section{Fulbright}




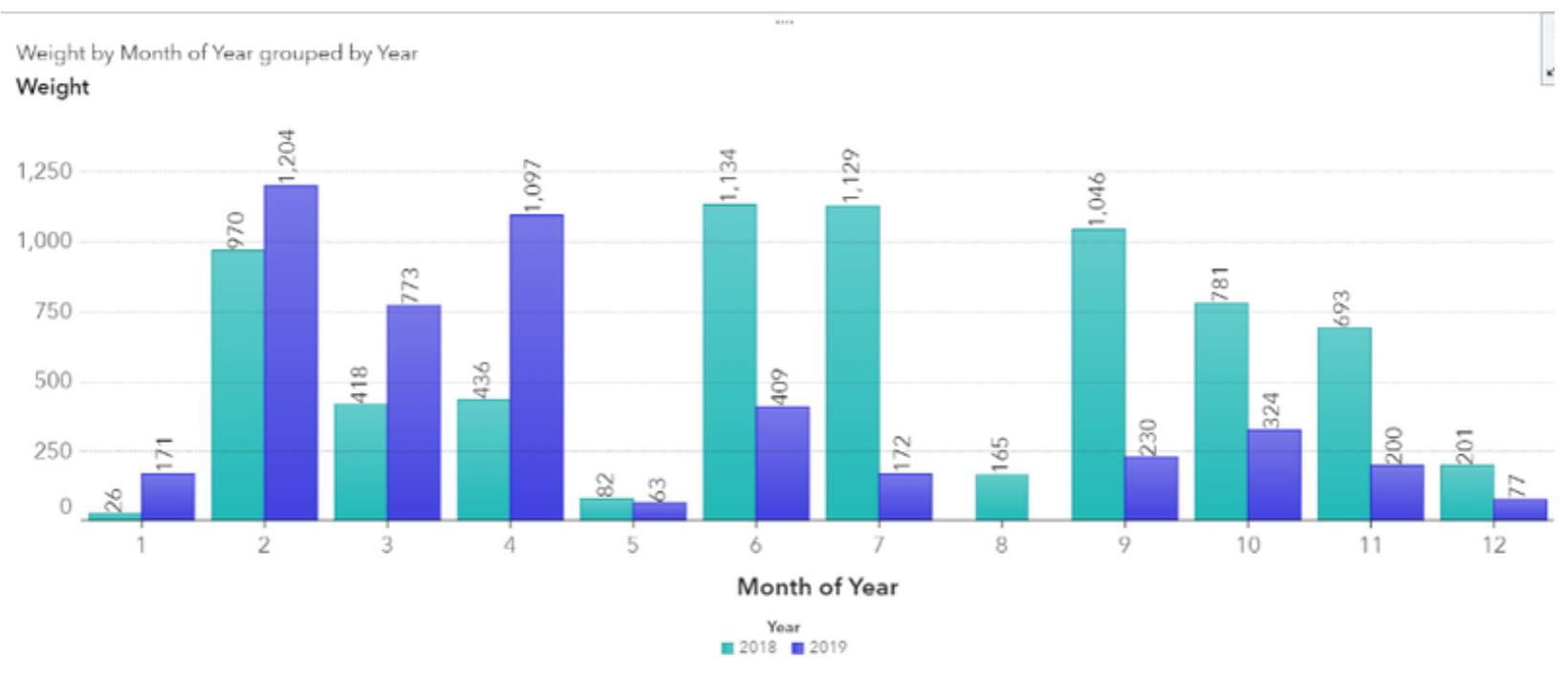

Fulbright was the leading dining hall for unused food in 2018. Fulbright was still the leading dining hall for 2019 but showed an overall decrease in unused food to 4,718 lbs, which represents a 33\% reduction in unused food. By the end of 2019, Fulbright had accomplished what the RFR program had been created to achieve: to minimize food waste.

When assessing the timeline for when Fulbright accomplished this achievement, a month-by-month comparison was evaluated (Figure 3). For all of 2018 and the first 4 months of 2019, the unused food recovered typically ranged from 400 to 1,200 lbs. The last six months of 2019 showed the food recovered typically ranging below 400 lbs. and as low as zero in August of 2019. For the busier months of September, October and November, the percentage decrease for each month was $78 \%, 59 \%$ and $71 \%$. This represents a sustainable improvement in food production with substantially less unused food prepared in the Fulbright Dining Hall.

\section{Figure 4:}




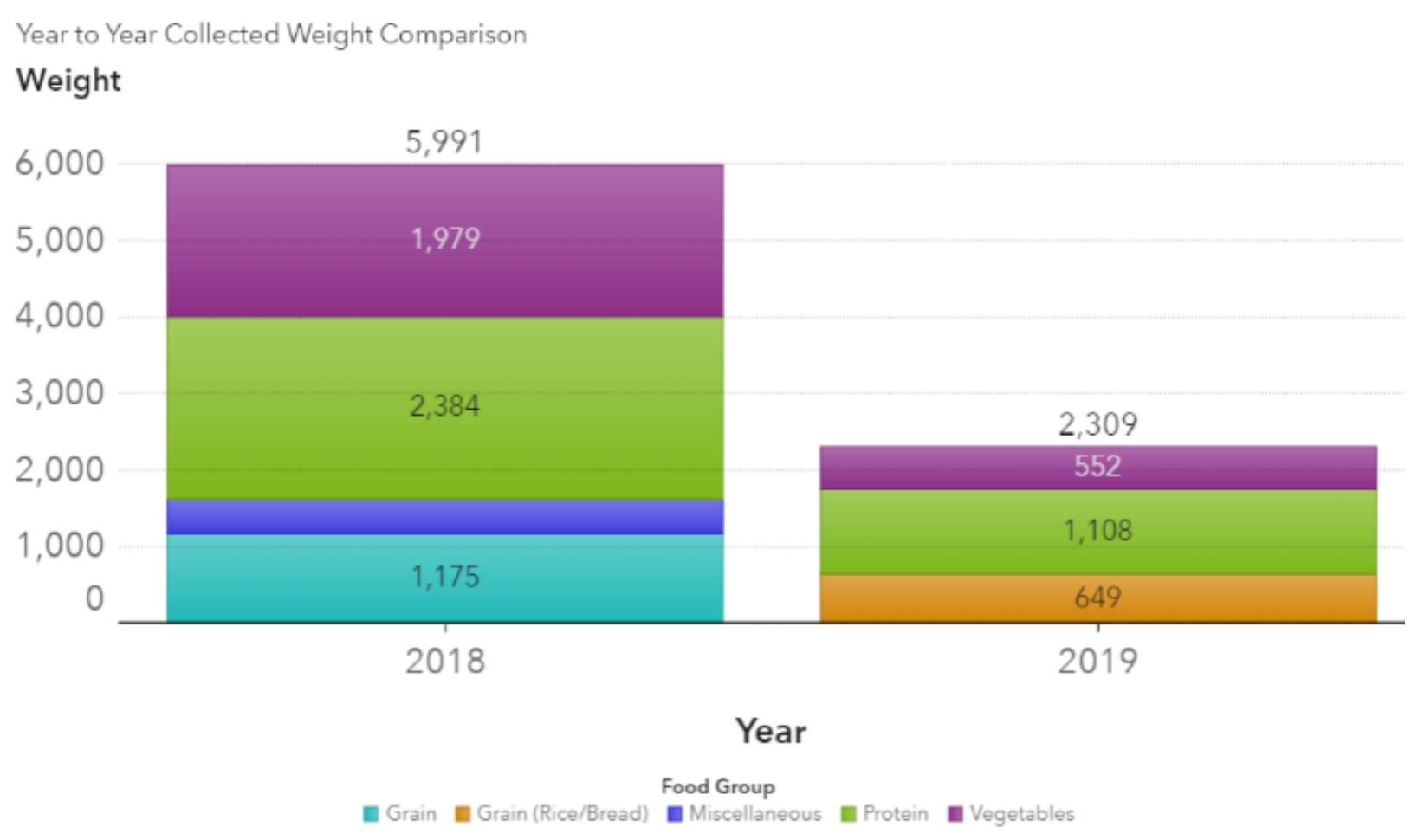

Part of the benefit of the data collected allows the evaluation of food categories that were impacted most by the RFR program goals. The top five food groups for 2018 and 2019 showed that the food recovered represented $90 \%$ of the total. The five 2018 food groups consisted of: 1) Grain, 2) Grain (Rice/Bread), 3) Pre-Packaged Foods, 4) Protein and 5) Vegetables (Figure 4). The Vegetable and Protein food groups showed the greatest year-to-year improvement with the vegetable group showing a $45 \%$ decrease and the protein group showing a $49 \%$ decrease in food recovery. These food group reductions show that dramatic improvement can be made by focusing on just a few categories. Finally, the top five comparison highlights how a change in organizational tracking can mask some of the accomplishments. The food group Grain, with 1,343 lbs recovered in 2018, was not used in 2019, indicating $100 \%$ of grains were not unused food. However, in 2019, the food group of Grain (Rice/Bread) can be assumed to encompass the same foods for both years. This recognition still indicated a $39 \%$ reduction.

\section{Figure 5:}

\section{Pomfret}




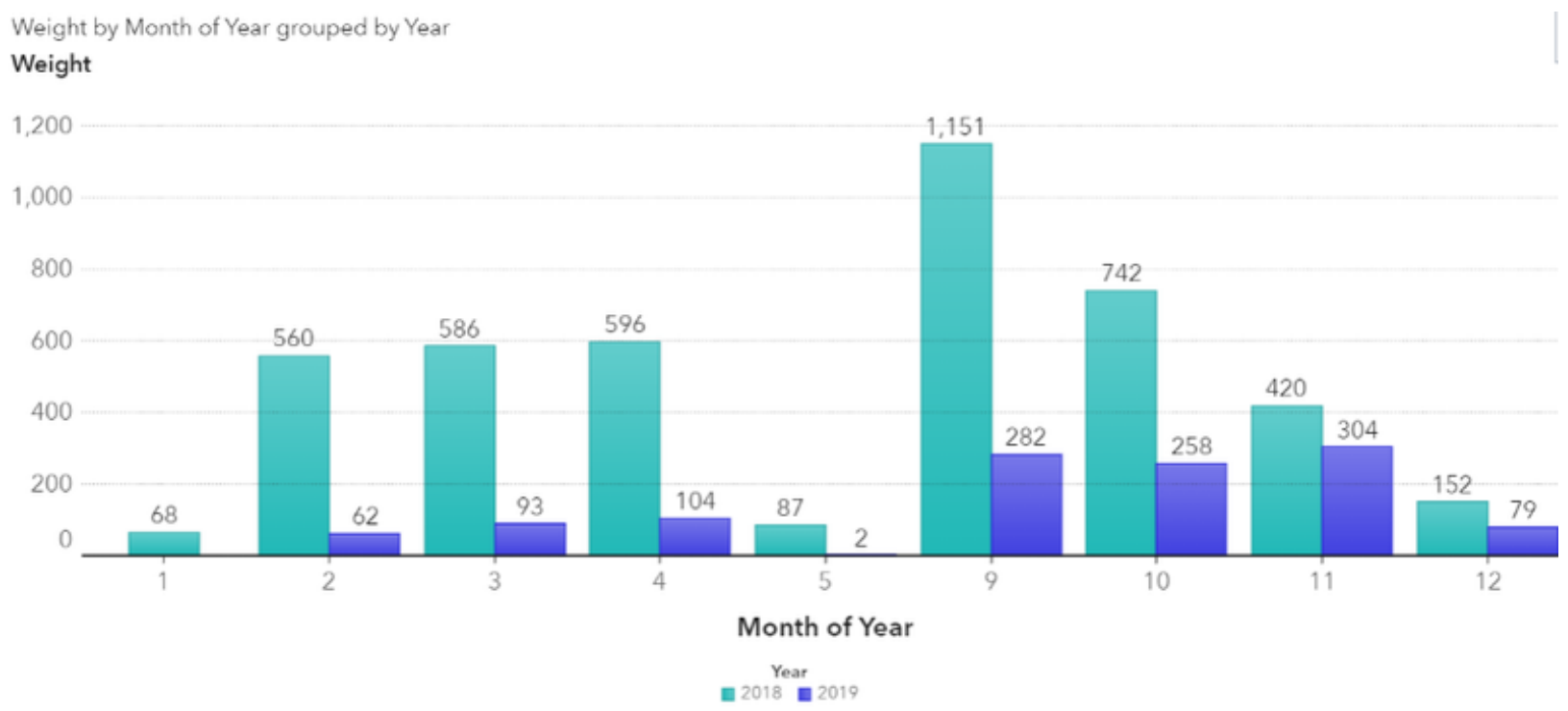

Pomfret dining hall showed an overall decrease in amount of unused food recovered from 2018 (4,362 lbs) and 2019 (1,185 lbs) by 73\% (Figure 2). By the end of 2019, Pomfret had accomplished what the RFR program had been created to achieve, just as Fulbright had, to minimize food waste.

When assessing the timeline for when Pomfret accomplished this achievement, a month-by-month comparison was evaluated (Figure 5). For all of 2018, the unused food recovered typically ranged from 60 to 1,151 lbs. The year 2019 showed the food recovered typically ranging below $60 \mathrm{lbs}$ to $300 \mathrm{lbs}$ and as low as zero in August of 2019. For the busier months of September, October and November, the percentage decrease for each month was $75 \%, 65 \%$ and $28 \%$. This represents a sustainable improvement in food production with substantially less unused food fixed in the Pomfret dining hall.

\section{Figure 6:}




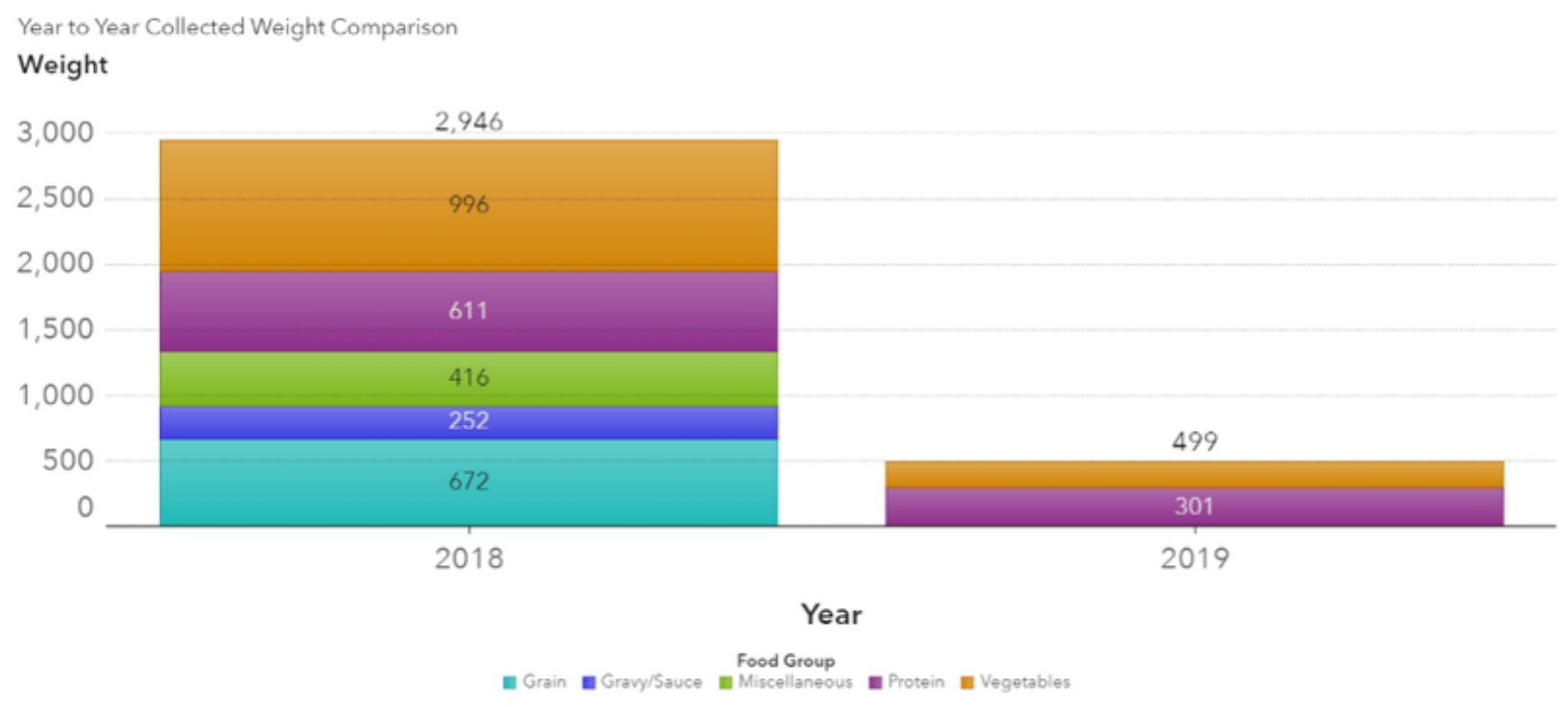

Part of the benefit of the data collected allows the evaluation of food categories that were impacted most by the RFR program goals. The top five groups showed that the recovered food represented $69 \%$ of the food recovered. When looking at the top 5 food groups that impacted the amount of recovered foods, the 2018 food groups consisted of: 1) Grain, 2) Gravy/Sauce, 3) Miscellaneous, 4) Protein and 5) Vegetables (Figure 6). The vegetable and protein food groups showed the greatest efficiency improvement with the vegetable group showing an $83 \%$ decrease and the protein group showing a $55 \%$ decrease. These food group reductions show that dramatic improvement can be made by focusing on just a few categories. Finally, the top five comparison highlights how a change in organizational tracking can mask some of the accomplishments. The food groups Grain, Gravy/Sauce, and Miscellaneous, with 740, 283, and 452 lbs. respectively recovered in 2018, was not used in 2019 , which indicates that $100 \%$ of these groups were not unused food.

\section{Brough}

Brough dining hall showed an overall increase in the amount of unused food recovered from 2018 (2,987 lbs.) and 2019 (4,160 lbs.) by 66\% (Figure 2). Brough did not accomplish what the RFR program had been created to achieve, which was a year-overyear reduction in food waste. When assessing the timeline for when Brough had an overall increase in recovered food, a month by month comparison was evaluated (Figure 7). Here it was discovered that, for the month of February, 2019 had an anomaly of 2,186 lbs recovered. If we were to ignore the recovered food for February 2019, RFR did realize a reduction in food waste from 2018 to 2019. For all of 2018, the unused food recovered typically ranged from 15 to 1,205 lbs. 2019, ignoring 


\section{Figure 7:}

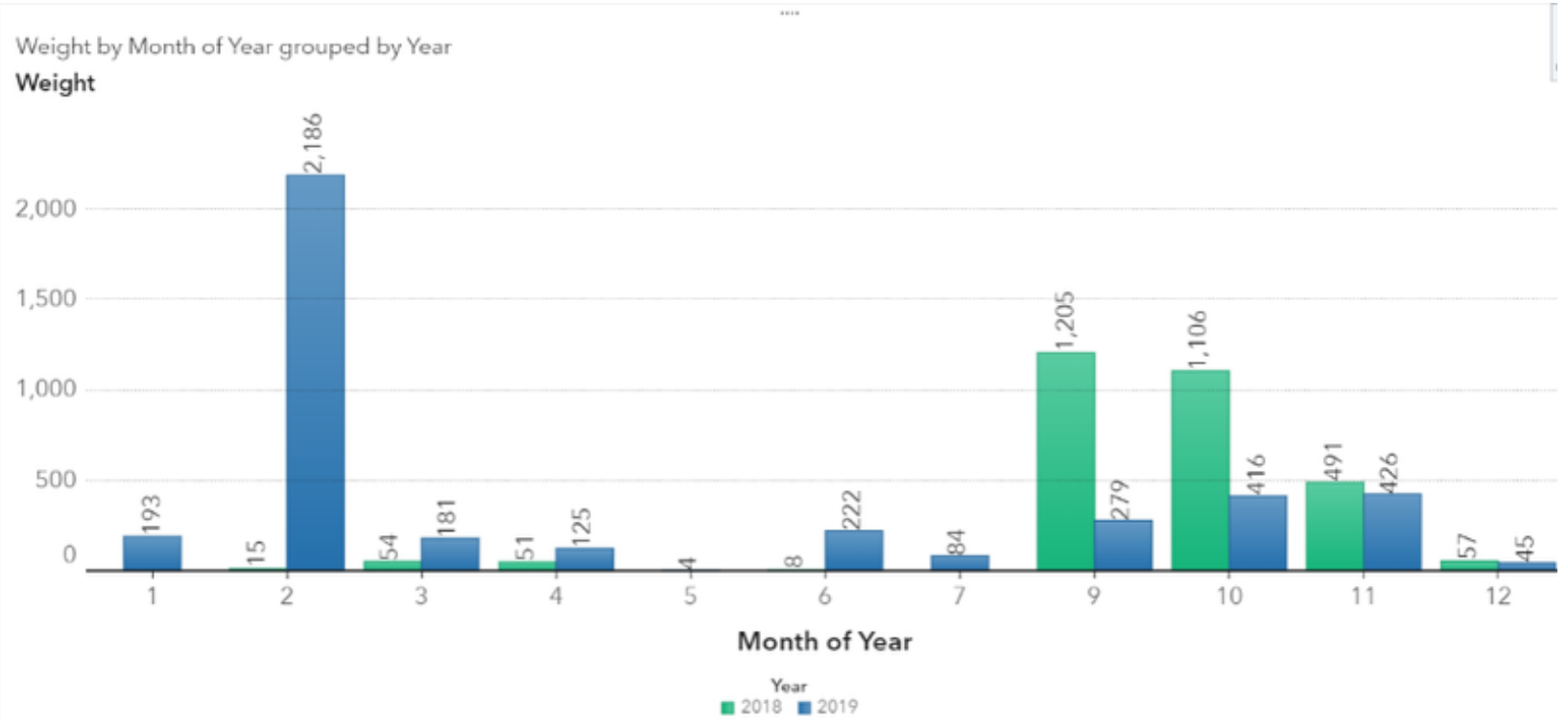

February, showed the food recovered typically ranging from 45 to $426 \mathrm{lbs}$. For the busier months of September, October and November, the percentage improvement for each month was 332\%, 166\% and 15\%. This represents a more unsustainable reduction in food production with more less unused food at Brough dining hall.

\section{Figure 8:}

Year to Year Collected Weight Comparison Weight

3,369

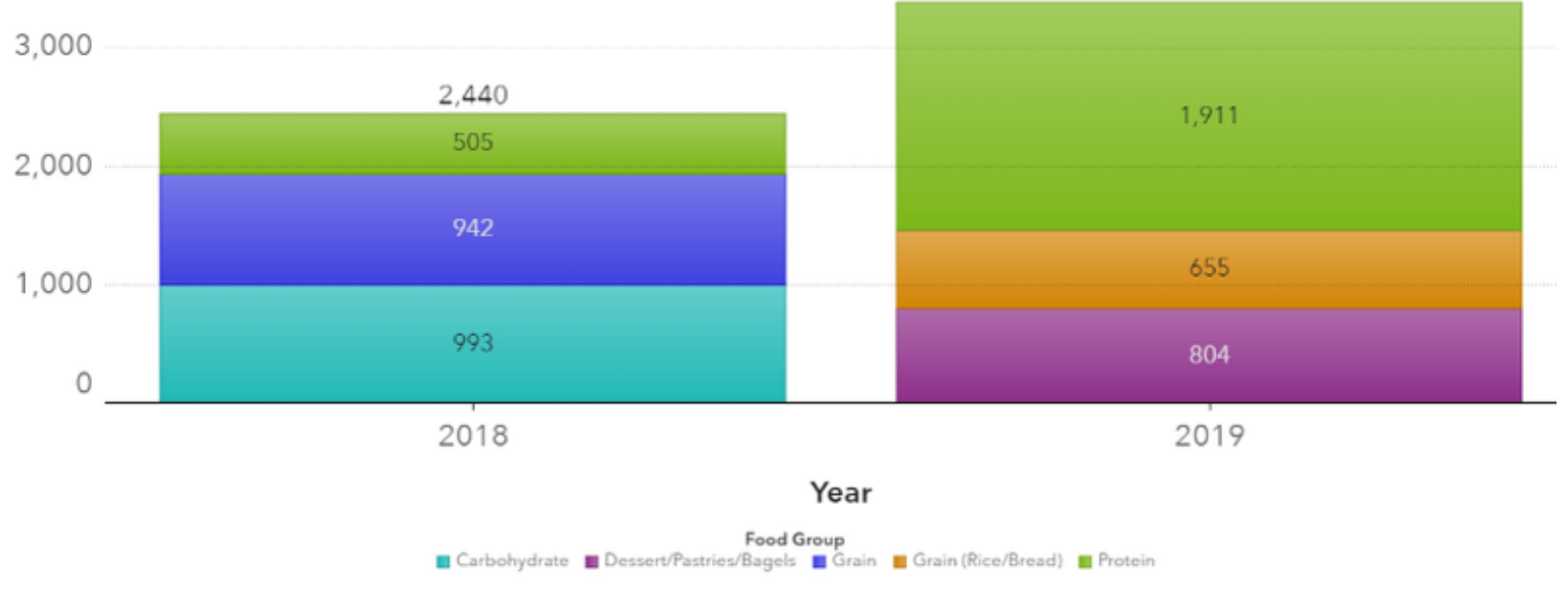




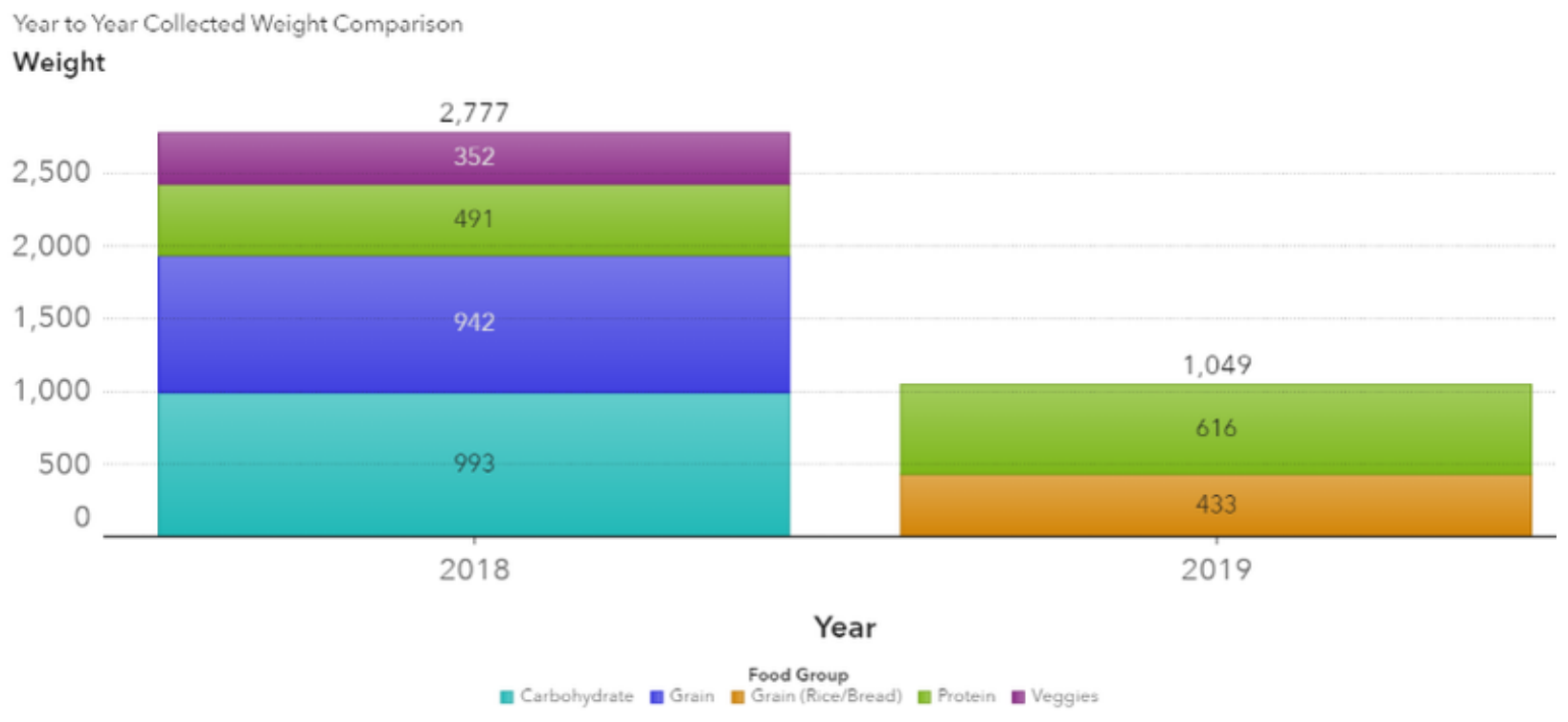

As with the other two dining halls, the top five groups at Brough showed that the recovered food represented $69 \%$ of the food recovered. When looking at the top 5 food groups, between 2018 and 2019, that impacted the amount of recovered foods, the 2018 food groups consisted of: 1) Protein, 2) Grain, 3) Carbohydrates, 4) Desserts/Pastries/Bagels and 5) Grain (Rice/Bread) (Figure 8). The Protein food group showed a reduction in control with a $136 \%$ increase. However, this assessment does not consider the anomaly of the extraordinary amount of food recovered in February 2019. The picture changes when taking this anomaly into account (Figure 9). An increased efficiency is noted with 2,777 lbs recovered in 2018 and 1,049 lbs recovered in 2019. The food groups addressed include: 1) Carbohydrates, 2) Grain, 3) Grain (Rice/Bread), 4) Protein and 5) Vegetables. Categorical decreases can be directly observed, but predominantly the decreases are associated with adjustments in collection methods, such as Carbohydrates and Grain (for 2018) being part of the Grain food group category in 2019.

\section{Figure 9:}

\section{Climate Action}




\begin{tabular}{|c|c|c|c|c|c|c|}
\hline & \multicolumn{2}{|c|}{ Fulbright } & \multicolumn{2}{|c|}{ Pomfret } & \multicolumn{2}{|c|}{ Brough } \\
\hline & Pounds Diverted & $\begin{array}{c}\text { Emissions Saved } \\
\text { (MTCO2E) }\end{array}$ & Pounds Diverted & $\begin{array}{c}\text { Emissions Saved } \\
\text { (MTCO2E) }\end{array}$ & Pounds Diverted & $\begin{array}{c}\text { Emissions Saved } \\
\text { (MTCO2E) }\end{array}$ \\
\hline September & 816 & -1.57 & 869 & -1.67 & 926 & -1.78 \\
\hline October & 457 & -0.88 & 484 & -0.93 & 690 & -1.33 \\
\hline November & 493 & -0.95 & 116 & -0.22 & 65 & -0.13 \\
\hline Dining Hall Total & 1766 & -3.4 & 1469 & -2.82 & 1681 & -3.24 \\
\hline
\end{tabular}

RFR's work, though originally initiated to be more responsible in consumption and reduce hunger in the northwest Arkansas area, has been beneficial to our climate. This calculation of environmental impact starts with a look at the comparison of the amount of food diverted from landfills between 2018 and 2019. The months of September, October and November were selected as the months that best represent the efforts of RFR. The pounds diverted number is the difference between weights of food recovered in 2018 compared to 2019. RFR's interventions in the dining halls achieved source reduction, allowing food to be saved and less food to be put up for recovery. This difference in amount recovered can be translated to emissions saved in 2019, because 2018 gives a template for the amount of food that would have been wasted. Between these two years, waste in the dining halls dropped and a total 4,916 lbs of waste was diverted, which allows the emission saved to be calculated (Figure 10).

\section{Figure 10:}

\section{Total Change in GHG Emissions (MTCO2E): -9.46}

This is equivalent to...

Removing annual emissions from 2 Passenger Vehicles

Conserving 1065 Gallons of Gasoline

Conserving 394 Cylinders of Propane Used for Home Barbeques

The emissions avoided measure is calculated through the EPA Waste Reduction Model. The resulting emission numbers represents "the full life-cycle benefits" of source reduction compared to landfilling or composting the food waste (EPA, 2020). Emissions saved is measured through the unit called metric tons carbon dioxide equivalency 
(MTCO2E), a unit designed to standardize the measurement of various greenhouse gas emissions into a singular component (EPA, 2014). The source reduction efforts across these years resulted in a reduction of 9.46 MTCO2E (Figure 11). This amount of emissions is the same as removing the annual emissions from 2 passenger vehicles or conserving 1,065 gallons of gas. Reducing emissions contributes to climate action by limiting global warming (EPA, 2020).

\section{Conclusion}

In order to donate this excess food to RFR's community partners, like Seven Hills homeless shelter and Salvation Army, RFR organizes volunteer distribution drivers to deliver what has been recovered from the dining halls. While these donations can vary significantly from week to week, they serve as a supplement to these community partners' efforts to address the local issue of food insecurityundefined. While this basic structure of the program remains the same year-to-year, the student-led board of Razorback Food Recovery works to both adapt the program to the specific conditions of every semester as well as create additional events to further the goals of food waste reduction, food security and responsible consumption of our resources. When creating the recovery schedules each semester, the board works to maximize the amount of food recovered by prioritizing the dining halls and days that produce the most food waste. Additionally, as food waste has decreased over the course of the program's implementation, the board has begun to research recovery opportunities off-campus in order to expand the program's reach. The Board also creates educational events like "Stop Food Waste Day" in order to teach students about the issue of food waste. As RFR learns more about how to achieve the goals that are part of its founding, new goals and expanding reach are ongoing efforts to become a more responsible organization.

\section{Limitations}

The Razorback Food Recovery Program at the University of Arkansas has always strived to effectively eliminate food waste on campus, and in turn, provide the agencies that serve food insecure people in the community with quality food through food recovery. Chartwells Dining Services is a campus auxiliary that are bound by datasharing restrictions, making it difficult to do analysis beyond recovery information. For future studies and more in-depth analysis, RFR would greatly benefit from foot traffic data. Chartwells Dining Services are protective of data they obtain through their operations. Data has been requested regarding purchasing information for food products and foot traffic data from dining halls throughout each 
semester/month/week/day as this data would be able to help RFR run analytics to hone in on what is causing food waste. RFR's contribution to the reduction in food waste within each dining hall is possible due to the sharing of data with Chartwells and the communication with their agents at each dining Hall. Changes in the more responsible production of food is credited to Chartwells' improvements in their operations. The provided data and presentations have had a positive impact on Chartwells, but the processes and improved efficiencies of Chartwells should be credited to their operational changes. When the data is input by student volunteers, there is always a chance for input error to create outliers or false information. There are continual operational changes to mitigate input error risk.

\section{Acknowledgements}

We thank Dr. Ron Freeze (University of Arkansas) for working with us and providing analysis of our data since 2018. We thank our supervisors Sage McCoy and Claire Allison (University of Arkansas, Center for Community Engagement) for reviewing our work and aiding our efforts in all our work. We thank the entire RFR student leadership boards - current and past - as we all share the same passion for service and change.

\section{References}

EPA. (2014, October). Retrieved from https://www.epa.gov/sites/production/files/201412/documents/ghgcalculatorhelp.pdfEPA. (2020).

Basic Information about Landfill Gas. Retrieved from Environmental Protection Agency: https://www.epa.gov/lmop/basic-information-about-landfill-gasEPA. (2020).

Food Recovery Hierarchy. Retrieved from EPA: https://www.epa.gov/sustainablemanagement-food/food-recovery-hierarchyEPA. (2020, November).

Waste Reduction Model. Kellams, L. (2020, July).

Arkansas Advocates for Children \& Families. Retrieved from Food Insecurity in Arkansas: https://www.aradvocates.org/wp-content/uploads/SNAPreport.webfinal.7.18.2020.pdfLisnic, R. (2016, July).

Center for Community Engagement. Retrieved from Student Food Insecurity: Assessment, Predictors, Consequences and Potential Solutions: https://service.uark.edu/services/pantry/foodinsecurityreport.pdfUnited Nations. (2020, December 16). 
12 Responsible Consumption and Production. Retrieved from Sustainable Development Goals: https://www.un.org/sustainabledevelopment/sustainable-consumptionproductionUnited Nations. (2020).

Goal 13: Take urgent action to combat climate change and its impacts. Retrieved from United Nations: https://www.un.org/sustainabledevelopment/climate-change/United Nations. (2020).

Goal 2: Zero Hunger. Retrieved from

https://www.un.org/sustainabledevelopment/hunger/

\section{Appendix A: Data Dictionary}

\begin{tabular}{|c|c|c|c|}
\hline Variable Name & Variable Type & Variable Examples & Variable Description \\
\hline TimeStamp & DATE & 2/3/2020 14:36:22 & $\begin{array}{l}\text { Time data entered } \\
\text { same as todays date } \\
\text { usually, most accurate } \\
\text { time data }\end{array}$ \\
\hline Today's Date & DATE & 1/31/2020 14:35:00 & $\begin{array}{l}\text { The day the data was } \\
\text { entered; normally the } \\
\text { same as the timestamp }\end{array}$ \\
\hline Dining Hall & VARCHAR(33) & Brough; Fulbright; & $\begin{array}{l}\text { The dining hall the food } \\
\text { was recovered from }\end{array}$ \\
\hline Weight & DECIMAL $(20,2)$ & $7.1 ; 4.7 ; 1.1$ & $\begin{array}{l}\text { How much weight, in } \\
\text { pounds, the recovered } \\
\text { food Weighed }\end{array}$ \\
\hline Food Group & VARCHAR(44) & $\begin{array}{l}\text { Protein; Vegetable; } \\
\text { Grain }\end{array}$ & $\begin{array}{l}\text { The food group the } \\
\text { food recovered is in }\end{array}$ \\
\hline Food More Specified & VARCHAR(83) & $\begin{array}{l}\text { Brown Rice Pilaf; } \\
\text { Chicken and } \\
\text { Dumplings; Chili }\end{array}$ & $\begin{array}{l}\text { The specific dish or } \\
\text { item the food } \\
\text { recovered is }\end{array}$ \\
\hline Food Storage & VARCHAR(16) & $\begin{array}{l}\text { Fridge; Freezer; } \\
\text { Hotline }\end{array}$ & $\begin{array}{l}\text { The way the food needs } \\
\text { to be stored or was } \\
\text { stored at the dining } \\
\text { hall. }\end{array}$ \\
\hline
\end{tabular}




\begin{tabular}{|c|c|c|c|}
\hline Quantity of Pans & $\operatorname{DECIMAL}(4,1)$ & $1 ; 2 ; 0$ & $\begin{array}{l}\text { The number of pans } \\
\text { (pans are how the food } \\
\text { is typically transported) } \\
\text { recovered from a } \\
\text { certain dining hall at } \\
\text { one time. }\end{array}$ \\
\hline Size of Pans & VARCHAR(22) & $\begin{array}{l}\text { Regular; Full sized } \\
\text { (Large) }\end{array}$ & $\begin{array}{l}\text { The size of the pan the } \\
\text { food was transported in }\end{array}$ \\
\hline Day of the Week & VARCHAR(3) & Mon; Tue; Wed & $\begin{array}{l}\text { The day of the week } \\
\text { that the food was } \\
\text { recovered. }\end{array}$ \\
\hline Day of the Month & BYTEINT & $28 ; 29 ; 30$ & $\begin{array}{l}\text { The day of the month } \\
\text { that the food was } \\
\text { recovered on. }\end{array}$ \\
\hline Month of the Year & BYTEINT & $8 ; 9 ; 10$ & $\begin{array}{l}\text { The number of the } \\
\text { month that the food } \\
\text { was recovered in. }\end{array}$ \\
\hline Year & SMALLINT & 2019; 2018 & $\begin{array}{l}\text { The year the food was } \\
\text { recovered in. }\end{array}$ \\
\hline Hour & BYTEINT & $9 ; 10 ; 22$ & $\begin{array}{l}\text { The hour of the day } \\
\text { that the food was } \\
\text { recovered. Recorded in } \\
\text { 24-hr notation. }\end{array}$ \\
\hline
\end{tabular}

